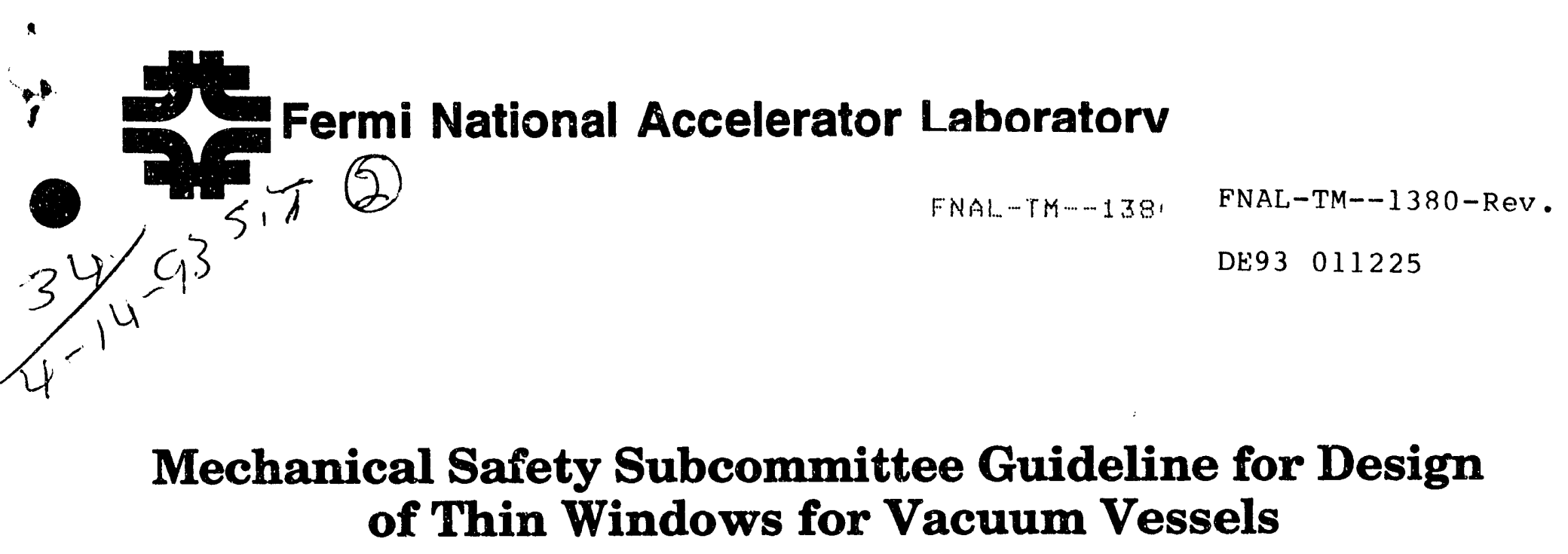

\author{
Jeffrey L. Western \\ Fermi National Accelerator Laboratory \\ P.O. Box 500, Batavia, Illinois 60510
}

March 1991

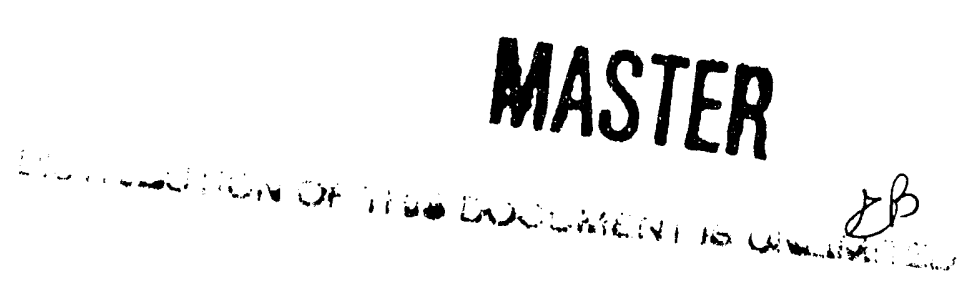

Operated by Universities Research Association Inc. under Contract No. DE-ACO2-76CHO3000 with the United States Department of Energy 
Disclaimer

This report was prepared as an account of work sponsored by an agency of the United States Government. Neither the United States Government nor any agency thereof, nor any of their employees, makes any warranty, express or implied, or assumes any legal liability or responsibility for the accuracy, completeness, or usefulness of any information, apparatus, product, or process disclosed, or represents that its use would not infringe privately owned rights. Reference herein to any specific commercial product, process, or service by trade name, trademark, manufacturer, or ctherwise, does not necessarily constitute or imply its endorsement, recommendation, or favoring by the United States Government or any agency thereof. The views and opinions of authors expressed herein do not necessarily state or reflect those of the United States Government or any agency thereof. 
TM-1380

March 6, 1991

\title{
Mechanical Safety Subcommittee Guideline for Design of Thin Windows for Vacuum Vessels
}

\author{
by: Jeffrey L. Western
}

\section{INTRODUCTION}

This guideline specifies the usage of thin windows for vacuum vessels in terms of their design and application at Fermilab.

2. SCOPE

2.1 This guideline is to be applied to vacuum vessels when the pressure differential across the window is less than or equal to fifteen (15) psid.

$$
d P \leq 15 \text { psid }
$$

2.2 This guideline will encompass thin windows consisting of circular, square and rectangular geometries.

2.3 This guideline shall fall under the scope of the "Fermilab Safety Manual", Vacuum Pressure Vessel Safety (5033).

2.4 Excluded from this guideline is windows for $\mathrm{LH}_{2}$ targets which are included under "Guidelines for the Design, Fabrication, Testing, Installation and Operation of $\mathrm{LH}_{2}$ Targets".

\section{GENERAL GUIDELINES}

3.1 A thin window is a diaphragm plate where the deflection is greater than $1 / 2$ of the thickness. From Article 10.11, page 457 "Formulas for Stress and Strain" Sixth Edition.

$y>t / 2$

(equation 3.1) 
3.2 The allowable stress for thin windows shall be the most stringent of the following:

$$
S=0.5 F_{u}
$$

or

$$
S=0.9 F_{y}
$$

\subsubsection{Where:}

$$
\begin{aligned}
\mathbf{S}= & \text { allowable stress }(\mathrm{psi}) \\
\mathbf{F}_{\mathbf{u}}= & \text { ultimate tensile strength }(\mathrm{psi}) \\
\mathbf{F}_{\mathbf{y}}= & \text { yield strength or stress to produce } 5 \% \\
& \text { elongation }(\mathrm{psi})
\end{aligned}
$$

3.3 Thin windows shall not be exposed to cyclic loading greater than 1000 load cycles. Negative load cycling is not allowed unless design and testing verifies performance.

3.4 The mounting flange shall have an edge radius to prevent the window from tearing.

3.5 Material documentation: Vendor material certification/ verification shall be included in window documentation.

3.6 Multi-layer mylar window: Mylar windows with a thickness

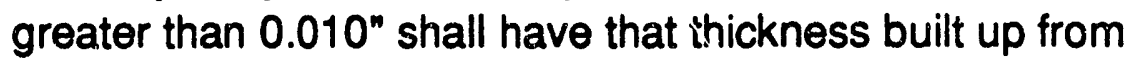
multiple layers of mylar, with no single layer more than $0.010^{n}$ thick.

\section{GUIDELINES FOR FLEXIBLE MATERIAL WINDOWS}

4.1 Flexible material circular windows such as mylar/kapton and titanium/stainless steel less than $0.003^{\prime \prime}\left(t<0.003^{\prime \prime}\right)$.

Design condition: held not fixed.

4.1.1 The allowable stress for circular windows shall be greater than the following: Derived from Equations 1 and 2, page 477, case number 4, page 478 "Formulas for Stress and Strain" Sixth Edition. 


$$
S>0.423\left(E q^{2} a^{2} / t^{2}\right)^{1 / 3}
$$

and the deflection is:

$$
y=0.662 \mathrm{a}(q a / E t)^{1 / 3}
$$

(equation 4.1b)

\subsubsection{Where:}

$$
\begin{aligned}
& t=\text { thickness of window (inch) } \\
& \mathbf{a}=\text { radius of window measured at O-ring on } \\
& \text { flange (inch) } \\
& \mathbf{q}=\text { uniform pressure on window (psid) } \\
& \mathbf{S}=\text { allowable stress (psi) } \\
& \mathbf{E}=\text { Young's modulus of window material (psi) } \\
& \mathbf{y}=\text { window deflection (inch) }
\end{aligned}
$$

4.2 Flexible material rectangular windows such as mylar/kapton and titanium/stainless steel less than $0.003^{\prime \prime}\left(t<0.003^{\prime \prime}\right)$.

Design condition: held not fixed.

4.2.1 The allowable stress for rectangular windows shall be greater than the following: From Brookhaven National Laboratory "Occupational Health and Safety Guide", Section 1.4.2, appendix B.

$$
S>K_{1}\left(E(q a / t)^{2}\right)^{1 / 3}
$$

and the deflection is:

$$
y=K_{2}\left(q a^{4} / E t\right)^{1 / 3}
$$

\subsubsection{Where:}

$$
\begin{aligned}
t_{1}= & \text { thickness of window (inch) } \\
\mathbf{K}_{\mathbf{1}}= & \text { stress constant based on ratio } a / b \text { (see table } \\
& \text { below) } \\
\mathbf{K}_{2}= & \begin{array}{l}
\text { deflection constant based on ratio } a / b \text { (see table } \\
\text { below) }
\end{array} \\
a= & \text { short side of rectangular window measured at } \\
& \text { O-ring (inch) }
\end{aligned}
$$



b = long side of rectangular window measured at O-ring (inch)
$q=$ uniform pressure on window (psid)
$\mathbf{S}=$ allowable stress (psi)
$E=$ Young's modulus of window material (psi)
$y=$ window deflection (inch)

4.2.3 Constant table for values of $K$ for rectangular windows:

b/a

1.0

1.1

1.2

1.3

1.4

1.5

1.6

1.7

1.8

1.9

2.0

3.0

$>3.0$

$$
K_{1}
$$

0.271

0.292

0.306

0.316

0.323

0.329

0.332

0.336

0.338

0.340

0.340

0.346

0.346
$K_{2}$

0.320

0.331

0.339

0.344

0.348

0.351

0.353

0.355

0.356

0.357

0.357

0.360

0.360

Note: $K_{1}$ values for maximum stress at center of window.

\section{GUIDELINES FOR RIGID MATERIAL WINDOWS}

5.1 Rigid material circular windows such as titanium and stainless steel greater than $0.003^{\prime \prime}\left(t>0.003^{\prime \prime}\right)$. Design condition: held and fixed.

5.1.1 The allowable stress for circular windows shall be greater than the stress obtained by solving by trial and error equation $5.1 \mathrm{~b}$ for deflection and then substitute into 5.1a. See equations 1 and 2, page 477, case number 3, page 478 "Formulas for Stress and Strain" Sixth Edition. 
$S>E(t / a)^{2}\left[K_{3}(y / t)+K_{4}(y / t)^{2}\right]$

(equation 5.1a)

and the deflection can be calculated from:

$q a^{4} / E t^{2}=K_{1}(y / t)+K_{2}(y / t)^{3}$

(equation 5.1b)

5.1.2 Where:
$t=$ thickness of window (inch)
$\mathbf{a}=$ radius of window measured at O-ring on flange (inch)
$q=$ uniform pressure on window (psid)
$\mathbf{S}=$ allowable stress (psi)
$\mathbf{E}=$ Young's modulus of window material (psi)
$\mathbf{y}=$ window deflection (inch)
$K_{1}=5.33 /\left(1-v^{2}\right)$
Note: $K$ values
$K_{2}=2.6 /\left(1-v^{2}\right)$
for maximum stress
$K_{3}=2.0 /(1-v)$
at center of window.
$K_{4}=0.976$
$v=$ poisson's ratio

5.2 Rigid material rectangular windows such as titanium and stainless steel greater than $0.003^{\prime \prime}\left(t>0.003^{\prime \prime}\right)$. Design condition: held and fixed.

5.2.1 The allowable stress for rectangular windows shall be greater than the stress obtained by soiving by trial and error equation 5.2b for deflection and then substitute into 5.2a. From Brookhaven National Laboratory "Occupational Health and Safety Guide", Section 1.4.2, appendix C.

$$
S>E(t / a)^{2}\left[K_{3}(y / t)+K_{4}(y / t)^{2}\right]
$$

and the deflection can be calculated from:

$$
q a^{4} / E t^{2}=K_{1}(y / t)+K_{2}(y / t)^{3}
$$


5.2.2 Where:

$$
\begin{aligned}
\mathbf{t}= & \text { thickness of window (inch) } \\
\mathbf{K}_{1}= & \text { stress constant based on ratio } a / b \text { (see table } \\
& \text { below) } \\
\mathbf{K}_{2}= & \text { deflection constant based on ratio } a / b \text { (see table } \\
& \text { below) } \\
\mathbf{a}= & \text { short side of rectangular window measured at } \\
& \text { O-ring (inch) } \\
\mathbf{b}= & \text { long side of rectangular window measured at } \\
& \text { O-ring (inch) } \\
\mathbf{q}= & \text { uniform pressure on window (psid) } \\
\mathbf{S}= & \text { allowable stress ( } p s i) \\
\mathbf{E}= & \text { Young's modulus of window material (psi) } \\
\mathbf{y}= & \text { window deflection (inch) }
\end{aligned}
$$

5.2.3 Constant table for values of $\mathrm{K}$ for rectangular windows:

$\begin{array}{lllll}\text { b/a } & \mathbf{K}_{\mathbf{1}} & \mathbf{K}_{\mathbf{2}} & \mathbf{K}_{\mathbf{3}} & \mathbf{K}_{\mathbf{4}} \\ & & & & \\ 1.0 & 72.5 & 30.5 & 22.3 & 2.7 \\ 1.1 & 60.9 & 27.6 & 21.3 & 2.7 \\ 1.2 & 53.2 & 25.7 & 20.4 & 2.7 \\ 1.3 & 47.9 & 24.6 & 19.7 & 2.7 \\ 1.4 & 44.3 & 23.7 & 19.3 & 2.7 \\ 1.5 & 41.5 & 23.1 & 18.9 & 2.7 \\ 1.6 & 39.8 & 22.7 & 18.7 & 2.7 \\ 1.8 & 37.5 & 22.2 & 18.3 & 2.7 \\ 2.0 & 36.1 & 22.0 & 18.0 & 2.7 \\ >2.0 & 35.2 & 21.4 & 17.6 & 2.7 \\ \text { Note: } & K_{3} \text { and } K_{\mathbf{4}} \text { values for maximum stress at the } \\ \text { midpoint of the long edge of window. }\end{array}$

\section{RESPONSIBILITY / DOCUMENTATION}

The responsibility and documentation for thin windows shall follow the "Fermilab Safety Manual", Vacuum Pressure Vessel Safoiy (5033). 


\section{APPENDIX A}

\section{EXAMPLE 1: Circular flexible window}

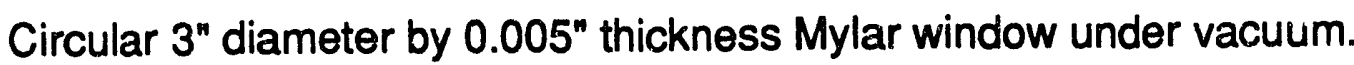

$$
\begin{aligned}
& t=0.005^{n} \text { : thickness of window (inch) } \\
& \mathrm{a}=1.5^{\mathrm{n}} \text { : radius of window measured at } \mathrm{O} \text {-ring on } \\
& \text { flange (inch) } \\
& q=14.7 \text { psi: uniform pressure on window (psid) } \\
& \mathrm{S}=0.5 \mathrm{~F}_{\mathrm{U}}=0.5 \times 25,000 \mathrm{psi}=12.500 \mathrm{psi} \text { or } \\
& 0.9 F_{y}=0.9 \times 15,000 \text { psi }=13,500 \text { psi: } \\
& \text { allowable stress (psi) } \\
& \mathbf{E}=500,000 \text { psi: Young's modulus of window material (psi) } \\
& y=\text { window deflection (inch) }<=\text { to be calculated }
\end{aligned}
$$

From TM-1380 Page 2, Section 4.1, Circular window with edge held but not fixed.

$$
\begin{aligned}
S & >0.423\left(E q^{2} \mathrm{a}^{2} / \mathrm{t}^{2}\right)^{1 / 3} \\
12,500 \mathrm{psi} & >0.423\left[(500,000)(14.7)^{2}(1.5)^{2} / 0.005^{2}\right]^{1 / 3} \\
12,500 \mathrm{psi} & >9.029 \mathrm{psi} \Rightarrow \text { Adequate }
\end{aligned}
$$

and the deflection is:

$$
\begin{array}{rlr}
y & =0.662 \mathrm{a}(\mathrm{qa} / \mathrm{Et})^{1 / 3} & \text { (equation 4.1b) } \\
y & =0.662(1.5)[(14.7)(1.5) /(500,000)(0.005)]^{1 / 3} \\
y & =0.205 \text { inch }<=\text { Deflection } \\
y & >t / 2 \\
\text { and: } \quad 0.205^{n} & >0.005^{n / 2} \\
0.205^{n} & >0.0025^{n} \Rightarrow \text { Adequate }
\end{array}
$$




\section{APPENDIX A}

EXAMPLE 2: Square flexible window

Square $3^{n}$ by $0.009^{n}$ thickness Kapton window under vacuum.

$t=0.009^{n}$ : thickness of window (inch)

$a=3.0^{\mathrm{N}}$ : short side of rectangular window measured at O-ring (inch)

b $=3.0^{\text {n: }}$ long side of rectangular window measured at O-ring (inch)

$q=14.7 \mathrm{psi}$ : uniform pressure on window (psid)

$S=0.5 F_{U}=0.5 \times 25,000 \mathrm{psi}=12,500 \mathrm{psi}$ or $0.9 F_{y}=0.9 \times 12,500 \mathrm{psi}=11.250 \mathrm{psi}$ :

allowable stress (psi)

$E=400,000$ psi: Young's modulus of window material (psi)

$y=$ window deflection (inch) $<=$ to be calculated

From TM-1380 Page 3, Section 4.2, Rectangular window with edge held but not fixed.

from table 4.2.3: for $b / a=3.0 / 3.0=1 \Rightarrow K_{1}=0.271 \& K_{2}=0.320$

$$
\begin{aligned}
S & >K_{1}\left[E(q a / t)^{2}\right]^{1 / 3} \quad \text { (equation 4.2a) } \\
11,250 \mathrm{psi} & >0.271\left[(400,000)(14.7)^{2}(3.0)^{2} /(0.009)^{2}\right]^{1 / 3} \\
11,250 \mathrm{psi} & >5760 \mathrm{psi} \Rightarrow \text { Adequate }
\end{aligned}
$$

and the deflection is:

$$
\begin{array}{rlrl}
y & =K_{2}\left(q a^{4} / E t\right)^{1 / 3} & \text { (equation 4.2b) } \\
y & =0.320\left[(14.7)(3.0)^{4} /(400,000)(0.009)\right]^{1 / 3} \\
y & =0.221 \text { inch }<=\text { Deflection } \\
y & >t 2 & \text { (equation 3.1) } \\
\text { and: } & 0.2 ? 1^{n} & >0.009^{n} / 2 \\
0.221^{n} & >0.0045^{n} \Rightarrow \text { Adequate }
\end{array}
$$




\section{APPENDIX A}

EXAMPLE 3: Circular rigid window

Circular $6^{\text {n }}$ diameter by $0.005^{n}$ thickness stainless steel (work hardened 302 S.S.) window under vacuum.

$$
\begin{aligned}
\mathbf{t}= & 0.005^{n}: \text { thickness of window (inch) } \\
\mathbf{a}= & 3.0^{n:} \text { radius of window measured at O-ring on } \\
& \text { flange (inch) } \\
\mathbf{q}= & 14.7 \mathrm{psi}: \text { uniform pressure on window (psid) } \\
\mathbf{S}= & 0.5 \mathrm{~F}_{\mathrm{u}}=0.5 \times 250,000 \mathrm{psi}=125,000 \mathrm{psi} \text { or } \\
& 0.9 \mathrm{~F}_{\mathrm{y}}=0.9 \times 150,000 \mathrm{psi}=135,000 \mathrm{psi}: \\
& \text { allowable stress (psi) } \\
\mathbf{E}= & 30 \mathrm{E} 6 \text { psi: Young's modulus of window material (psi) } \\
\mathbf{v}= & 0.3: \text { poisson's ratio } \\
\mathbf{y}= & \text { window deflection (inch) }<=\text { to be calculated }
\end{aligned}
$$

From TM-1380 Page 4, Section 5.1, Circular window with edge held and fixed.

from section 5.1.2: for $v=0.3 \Rightarrow K_{1}=5.86, K_{2}=2.86, K_{3}=2.86, K_{4}=.976$

deflection is: $\quad q a^{4} / E t^{4}=K_{1}(y / t)+K_{2}(y / t)^{3}$

(equation 5.1b)

$$
\begin{aligned}
14.7(3.0)^{4} / 30 \mathrm{E} 6(.005)^{4} & =5.86(y / .005)+2.86(y / .005)^{3} \\
y & =0.14 \text { inch }<=\text { Deflection......solved by trial and error }
\end{aligned}
$$

where:

$$
y>t / 2
$$

(equation 3.1)

$$
0.14^{n}>0.005^{n / 2}
$$$$
0.14^{n}>0.0025^{n} \Rightarrow \text { Adequate }
$$

stress is:

$$
S>E(t / a)^{2}\left[K_{3}(y / t)+K_{4}(y / t)^{2}\right]
$$

$$
\begin{aligned}
& 125,000 \text { psi }>(30 \mathrm{E} 6)(.005 / 3.0)^{2}\left[2.86(.14 / .005)+0.976(.14 / .005)^{2}\right] \\
& 125,000 \mathrm{psi}>38.817 \mathrm{psi}=>\text { Adequate }
\end{aligned}
$$




\section{APPENDIXA}

\section{EXÁMPLE 4: Rectangular rigid window}

Rectangular $6^{n} \times 9^{n}$ by $0.006^{n}$ thickness titanium (6AL-4V) window under vacuum.

$$
\begin{aligned}
& t=0.006^{n}: \text { thickness of window (inch) } \\
& \text { a }=6.0^{n} \text { : short side of rectangular window measured at } \\
& \text { O-ring (inch) }
\end{aligned}
$$

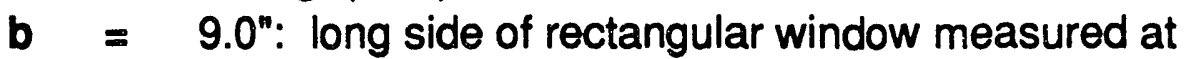

$$
\begin{aligned}
& \text { O-ring (inch) } \\
& q=14.7 \text { psi: uniform pressure on window (psid) } \\
& S=0.5 F_{u}=0.5 \times 130,000 \mathrm{psi}=65.000 \mathrm{psi} \text { or } \\
& 0.9 F_{y}=0.9 \times 120,000 \mathrm{psi}=108,000 \mathrm{psi} \text { : } \\
& \text { allowable stress (psi) } \\
& E=16 \mathrm{E} 6 \text { psi: Young's modulus of window material (psi) } \\
& v=0.3 \text { : poisson's ratio } \\
& y=\text { window deflection (inch) }<=\text { to be calculated }
\end{aligned}
$$

From TM-1380 Page 5, Section 5.2, Rectangular window with edge held and fixed.

from table 5.2.3: for $b / a=1.5 \Rightarrow K_{1}=41.5, K_{2}=23.1, K_{3}=18.9, K_{4}=2.7$

deflection is: $\quad \mathrm{qa}^{4} / E t^{4}=K_{1}(y / t)+K_{2}(y / t)^{3}$

(equation 5.2b)

$$
14.7(6.0)^{4 / 16 E 6}(.006)^{4}=41.5(y / .006)+23.1(y / .006)^{3}
$$

$y=0.21$ inch $<=$ Deflection......solved by trial and error

where:

$$
\begin{aligned}
y & >t / 2 \\
0.21^{n} & >0.006^{\prime \prime} / 2 \\
0.21^{\prime \prime} & >0.003^{n} \Rightarrow \text { Adequate }
\end{aligned}
$$

stress is:

$$
S>E(t / a)^{2}\left[K_{3}(y / t)+K_{4}(y / t)^{2}\right]
$$

$$
\begin{aligned}
& 65,000 \mathrm{psi}>(16 \mathrm{E} 6)(.006 / 6.0)^{2}\left[18.9(.21 / .006)+2.7(.21 / .006)^{2}\right] \\
& 65,000 \mathrm{psi}>63.504 \mathrm{psi} \Rightarrow \text { Adequate }
\end{aligned}
$$




\section{Practical Guidelines and Parameters for Thin Windows Used on Vacuum Vessels. $\quad$ Addendum to FERMILAB-TM-1380}

Extracted in part from Brookhaven National Laboratory Occupational Health and safety Guide (Glass and Plastic Window Design for Pressure Vessels 1.4.2 , Feb.,1980)

1. Parameters The following distance relationships should be observed, see figure $1,2 \& 3$

(a) The distance from the bolt hole to O-ring groove (B) shall be at least $2 / 3$ of the bolt diameter.

(b) The distance from the O-ring groove to the window opening (A) should be at least $1 / 8^{\circ}$ plus the edge radius.

(c) The window opening edge radius should be a minimum of 15 times the window thickness although 25 is preferred.

(d) For rectangular window mounts, the corner radius shall be a minimum of 0.15 of the shortest span of the window opening, see figure 3.

\section{Guidelines}

(a) Clamping surfaces should be flat to within $0.0015^{\circ} /$ foot.

(b) The clamping bolts shall be designed to exert a clamping force that is a minimum of 3 times the force applied to the window.

(c) The clamping ring must be rigid enough to maintain adequate clamping force between bolts.

(d) Flat washers shall be used under the bolt heads to prevent galling and to ensure the application of the proper torque value.

(e) All bolt holes, in the window, shall be punched with a sharp edged punch. Debur all holes after punching, do not burn the holes. Normal clearance hole practice should be applied.

(f) All surfaces shall be 64 micro-inches or better and free of burrs and sharp edges. 
(a) The clamping ring and vessel wall must be rigid enough to prevent any local deflections that would permit angular rotation of the window edges.

(b) The window must have significant flexural stiffness. See notes $1 \& 2$ of figure 2 .

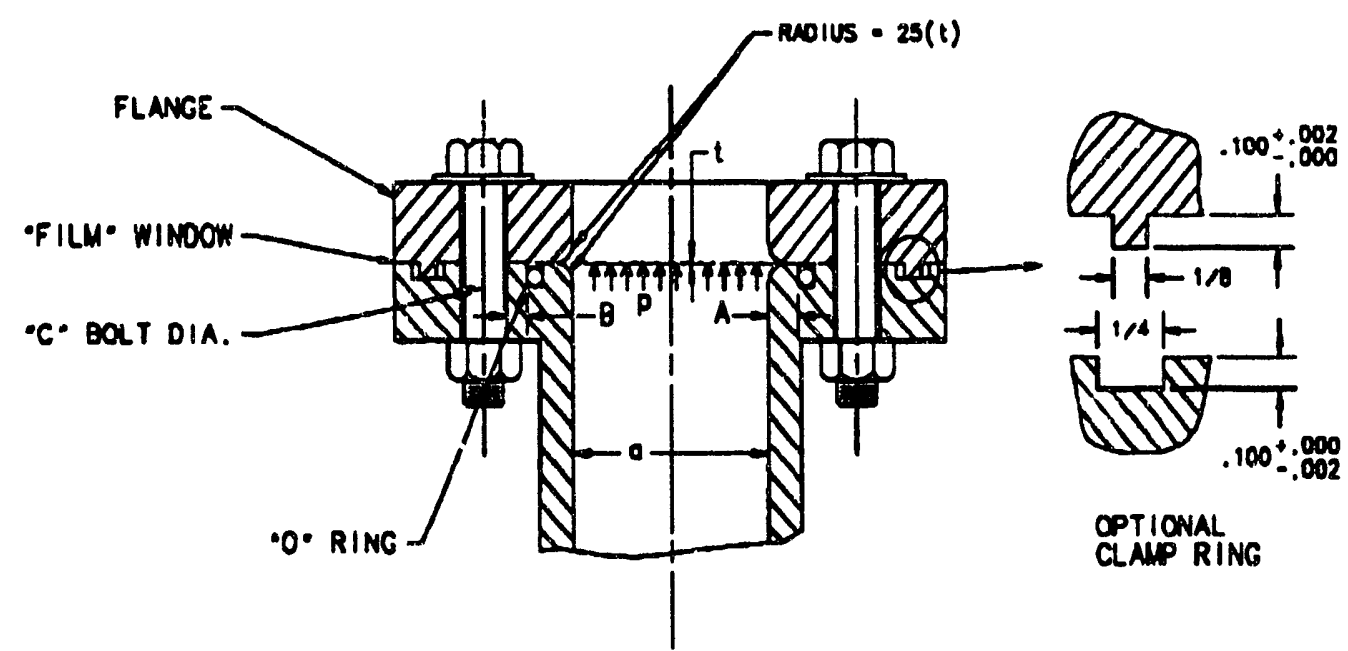

Notes:

1-C.ANP RING (OPTIONML) PROVIDES ADDED HOLDINC FOR THIN WIRDOWS (MAX. THKNESS .042

2-WINOOW MOUNT IS GLASSEC "HELO BUT NOT FIXEO" CNLY IF D/E (O/T) 2500

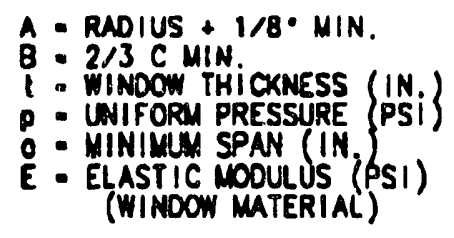

3-THIS MOWT CANNT BE USED FOR WINDOWS MADE OF BRITTLE MATERIAL SUCH AS GLASS, QUARTZ OR ME'TML METHACRYLATE

FIG. : 


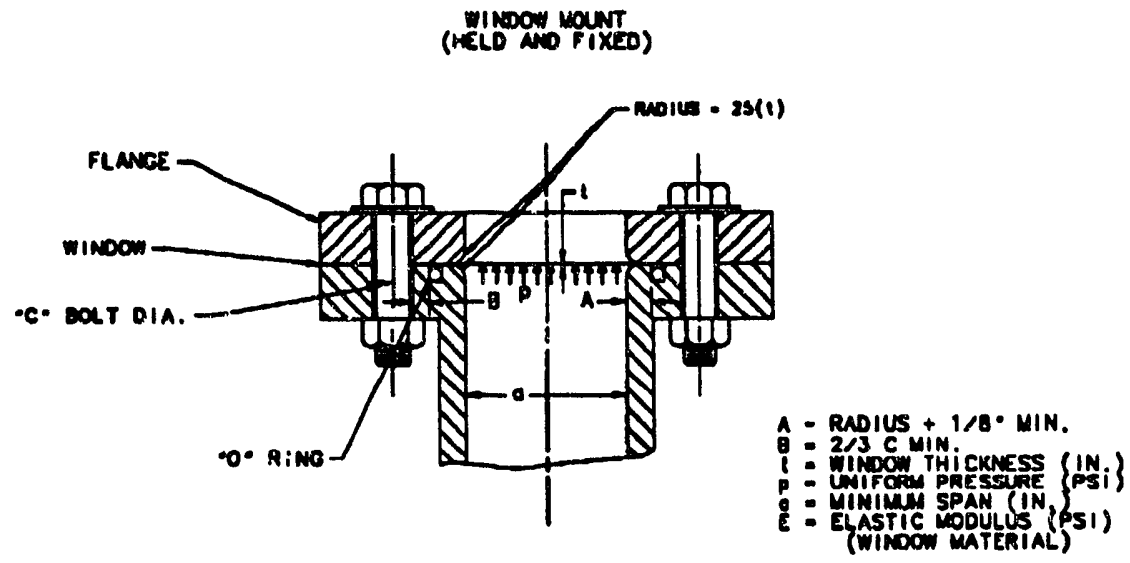

Notes:

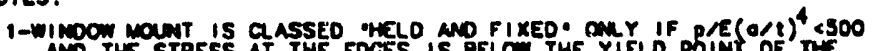
ATOOW STRESIA.

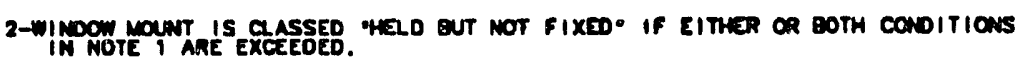

FIG. 2

FLAMGE for RECTANGULAR FILM WINDOWS

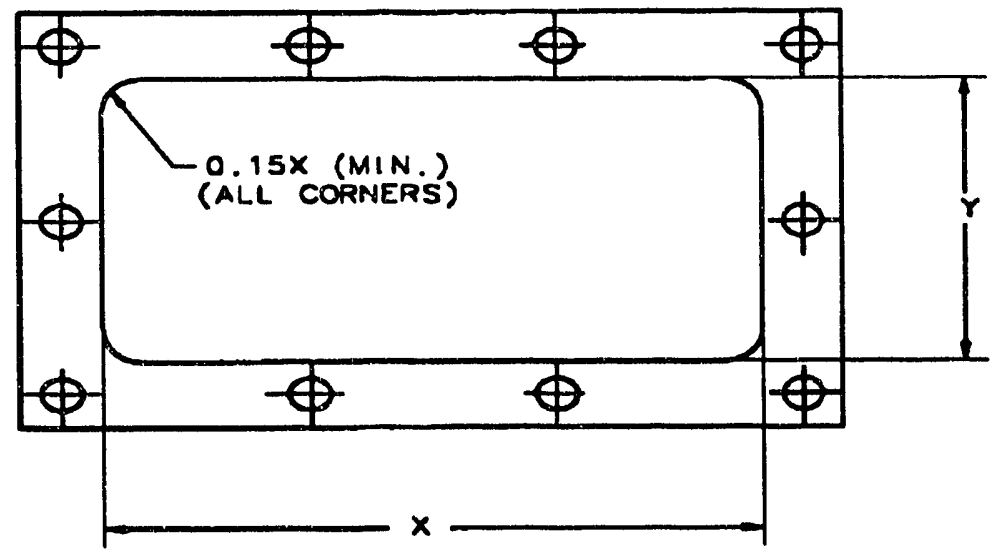

NOTES:

1 -WHERE -Xं IS SMALLER OR EQUAL TO "Y
2-ALL OTHER DIMENSIONS, REFER TO FIG. I \& 2

FIG. 3 

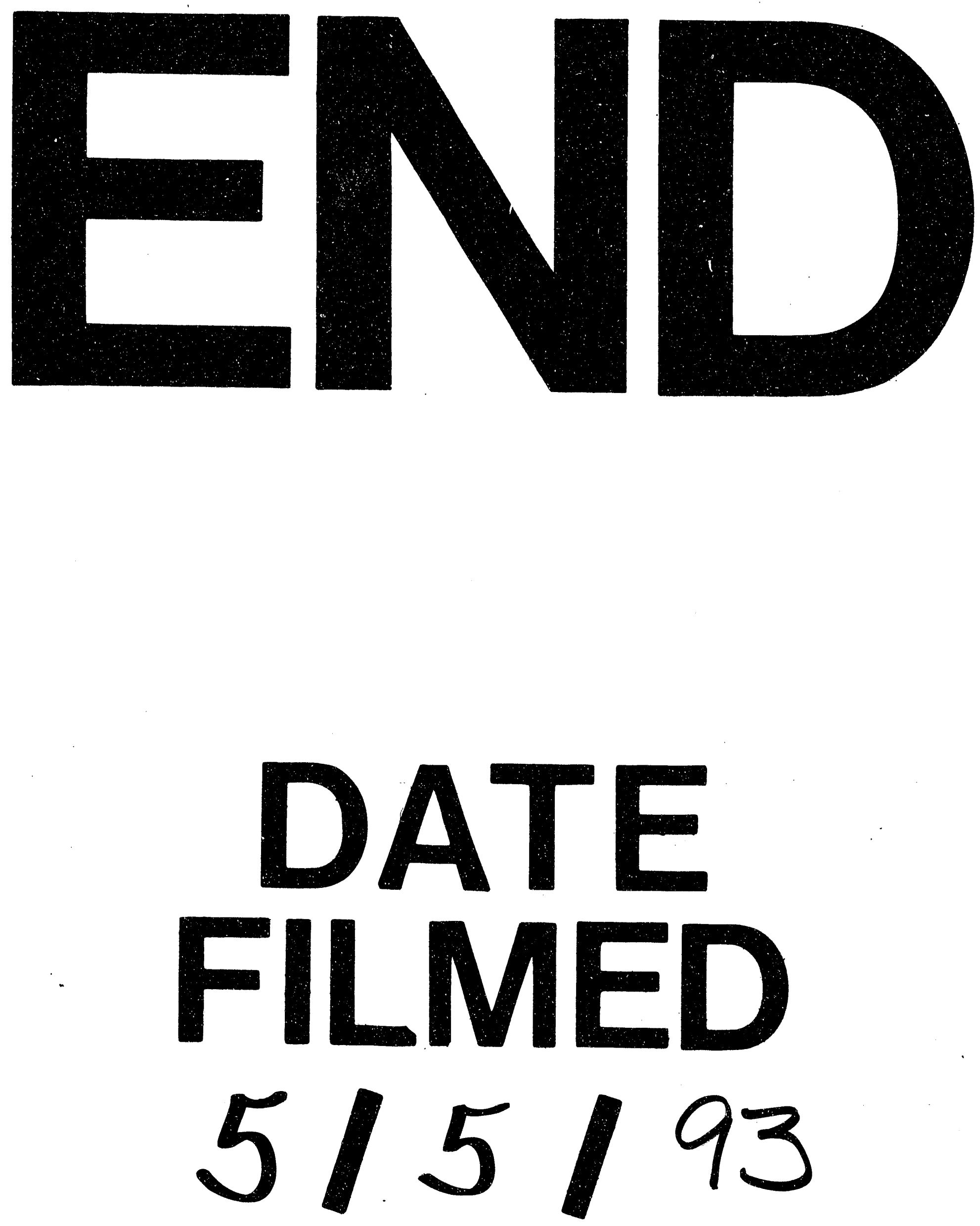
